\title{
Proses Pengembangan Daya Kritis Mahasiswa dalam Mata Kuliah Nihonjijou Melalui Pembelajaran Berbasis Proyek
}

\author{
Lispridona Diner \\ Universitas Negeri Semarang \\ lisjoost@yahoo.com
}

DOI: $10.18196 /$ jjlel.4131

\begin{abstract}
Abstrak
Mengenalkan budaya Jepang pada pembelajar bahasa Jepang diharapkan dapat meningkatkan minat mereka terhadap belajar bahasa Jepang. Mengenal budaya Jepang juga dapat diperoleh dalam perkuliahan yang lain seperti kaiwa, dokkai, chokai Pembelajaran budaya Jepang selama ini sudah baik yaitu menggunakan dua kegiatan kelas yaitu kegiatan "wakaru" dan "tanoshii".Dari kenyataan di atas, maka peneliti mempraktekkan kegiatan yang berbeda dari sebelumnya yaitu pembelajaran berbasis proyek. Tujuan dari penelitian ini adalah pembelajaran bahasa Jepang melalui pembelajaran berbasis proyek untuk menciptakan proses pembelajaran mandiri dan mahasiswa dapat memiliki daya pikir kritis.

Metode penelitian yang dgunakan yaitu metode deskriptif kualitatif. Populasi dan sampel penelitian ini mahasiswa semester 1 tahun ajaran 2019/2020 yang mengikuti perkuliahan nihonjijo sebanyak 32 mahasiswa. Teknik pengumpulan data yang digunakan adalah observasi dan angket.

Hasil observasi menunjukkan, mahasiswa dapat berpikir kritis: terdapat tema "ninja" tidak dalam lingkup budaya, kreatif: tidak ada gambar atau tema yang sama yang mahasiswa pilih dan mandiri: mendapatkan informasi awal dari berbagai sumber dalam menyelesaikan poyek pembelajaran. Hasil angket menunjukkan pembelajaran nihonjijo melaui pembelajaran berbasis proyek 94\% mahasiswa yang mengikuti perkuliahan nihonjijo berbasis proyek dapat menjadikan mahasiswa dapat mengungkapkan daya pikir kritis melalui penyampaian ide dan gagasan dalam kelompok dan 100\% dapat belajar mandiri.
\end{abstract}

Kata kunci: Mahasiswa; Budaya Jepang; Pembelajaran berbasis proyek

\footnotetext{
Abstract

(Title: Japanese Culture Learning Through Project-Based Learning In Basic Japanese Basic Learners) Introducing Japanese culture to Japanese
} 
language learners is expected to increase their interest in learning Japanese. Getting to know Japanese culture can also come from other lectures such as kaiwa, dokkai, chokai. Learning Japanese culture has been good so far, namely using two-class activities, "wakaru" and "tanoshii" activities. From the above facts, the researchers practiced different activities from previously that was project-based learning. The purpose of this research is Japanese learning through project-based learning to create an independent learning process, and students can have critical thinking. The research method used descriptive qualitative method. The population and sample of this study were 32 first semester students in the 2019/2020 school year who attended nihonjijo lectures. Data collection techniques used were observation and questionnaires. The observations showed that students could think critically. In essence, there is a "ninja" theme not in the cultural, creative sphere: There are no pictures or the same topics that students choose and are independent: get preliminary information from various sources in completing the learning project. The results of the questionnaire showed that nihonjijo learning through projectbased learning 94\% of students taking nihonjijo project-based lectures could make students express critical thinking through the delivery of ideas and ideas in groups and 100\% could learn independently.

Keywords: learners; Japanese culture; project-based learning

\section{PENDAHULUAN}

Era revolusi industri 4.o merupakan era dimana kemajuan teknologi berkembang pesat. Sejalan dengan itu, bahasa asing semakin banyak diminati oleh pembelajar bahasa di Indonesia. Di Indonesia, selain bahasa Inggris sebagai bahasa Internasional bahasa asing juga diperlukan dalam dunia kerja. Kebutuhan masyarakat terhadap bahasa asing, maka bahasa asing seperti bahasa Jepang, bahasa Mandarin, bahasa Korea dan bahasa Perancis diadakan dalam kurikulum pendidikan formal mulai dari pendidikan SD hingga pendidikan Tinggi.

Universitas Negeri Semarang sebagai Perguruan Tinggi dalam bidang Pendidikan pun menyelenggarakan program studi pendidikan bahasa Jepang. Program studi pendidikan bahasa Jepang, salah satu tujuannya mencetak lulusan yang bergerak dibidang pendidikan yaitu menjadi seorang guru atau pendidik bahasa Jepang. 
Dalam kurikulumnya, pembelajaran bahasa Jepang tingkat dasar terdapat pembelajaran budaya Jepang yang disebut nihonjijo. Tidak bisa dipungkiri, belajar bahasa Jepang, baik secara langsung maupun tidak langsung mengenal dan mempelajari budaya Jepang. Hal ini sejalan dengan yang dikatakan oleh Koentjaraningrat sebagaimana dikutip Chaer bahwa bahasa bagian dari kebudayaan. Hubungan antara bahasa dan kebudayaan merupakan hubungan subordinatif, suatu bahasa berada di bawah lingkup kebudayaan (2003:67). Sama dengan yang diungkapkan oleh Hashimoto, 2015:41 dalam artikelnya berjudul 日本語教育における[日本事情]一初級 日本語教材に見られる [日本事情]一menyatakan bahwa pendidikan bahasa Jepang dan nihonjijou memiliki hubungan erat dalam sosial dan budaya. Dengan mengenal keadaan Jepang (nihonjijo), maka pendidikan bahasa Jepang dapat dipelajari dari sudut pandang orang Jepang.

Berdasarkan hasil studi pendahuluan melalui penyebaran angket kepada mahasiswa semester 1 angkatan 2019, diperoleh hasil bahwa 70\% mahasiswa lebih berminat terhadap budaya Jepang dibandingkan pembelajaran bahasanya. merupakan salah satu alasan mereka memilih program studi pendidikan bahasa Jepang.

Mengenalkan budaya Jepang pada mahasiswa bahasa Jepang diharapkan dapat meningkatkan minat mereka terhadap belajar bahasa Jepang. Mengenal budaya Jepang juga dapat diperoleh dalam perkuliahan yang lain seperti kaiwa, dokkai, dan chokai. Pembelajaran budaya Jepang selama ini sudah baik yaitu menggunakan dua kegiatan kelas yaitu kegiatan wakaru (pada kegiatan ini, pembelajar memahami geografi Jepang, cara berpikir orang Jepang, cara berkomunikasi dengan orang Jepang, kebiasaan orang Jepang, rumah Jepang, baju tadisional Jepang, cara mengolah sampah di Jepang, angkutan umum) dan tanoshii (kegiatan bunka taiken/mengalami budaya Jepang seperti cara pakai yukata, shodo, origami, masak masakan Jepang). 
Dalam perkuliahan nihonjijo, perlu sebuah keterampilan mengajar dari pengajar untuk menyampaikan materi nihonjijo dengan tetap menghargai budaya Indonesia, akan tetapi bukan berarti pengajar yang bukan ahli kebudayaan tidak dapat mengajar tentang budaya Jepang. Dalam pembelajarannya bukan hanya sekedar teori, diperlukan contoh secara kongkrit.

Hal ini dikarenakan ruang lingkup budaya Jepang sangat luas. Matsumoto (2016:6), mengungkapkan bahwa keadaan dan budaya Jepang terbagi menjadi dua:1). Informasi penting tentang kehidupan masyarakat (hubungan interpersonal (対人関係): salam(挨拶), penamaan/penyebutan hormat (名前 - 敬称), hubungan atasan dan bawahan (上下関係), hubungan uchisoto (内外関係). Kehidupan (生活): tempat tinggal(住居), masakan(料 理・食べ物), pakaian (kimono 着物・ seragam 制服), pekerjaan (仕事・職 業), struktur keluarga (家族構成), kehidupan (sekolah 学校生活· seharihari 日常生活) dsb. Sistem masyarakat(社会システム): sistem lalu lintas (交 通システム), infranstruktur (生活インフラ), komunikasi (通信), media massa (メディア), sekolah (学校), keuangan (金融), perawatan kesehatan (医療), administrasi (行政), aturan masyarakat (社会ルール). Kebiasaan (習 慣/慣習): kesopanan (礼儀 - 作法), upacara pernikahan dan kematian (冠婚 葬祭), acara sepanjang tahun (年中行事), pemberian hadiah (贈答)). 2). Informasi penting untuk memahami secara dalam tentang budaya (kebiasaan - seni pertunjukkan (伝統 - 芸能): upacara minum teh (茶道), merangkai bunga (華道), seni menulis (書道), pertunjukkan tradisional (伝統 芸能), judo (柔道), karate (空手), sumo (相撲), perayaan (祭), permainan tradisional Jepang (伝統的な遊び), subkultur サブカルチャー (film 映画, drama ドラマ, komik 漫画, anime アニメ, musik 音楽), olah raga (スポーツ). Ilmu humaniora (人文科学・社会): politik (政治), ekonomi (経済), 
pendidikan (教育), sejarah (歴史), agama (教育). Lingkungan alam (自然環 境): geografi (地理), iklim (気候)).

Berdasarkan observasi pada studi pendahuluan, kegiatan kelas pada mahasiswa semester 1 sudah menunjukkan peningkatan minat mahasiswa terhadap budaya serta bahasa Jepang. Hal tersebut ditunjukkan saat di kelas mahasiswa menggunakan kosa kata bahasa Jepang dalam bertanya ataupun menjelaskan ketika berdiskusi atau berinteraksi.

Namun disisi lain mahasiswa belum memiliki daya pikir kritis dan kemandirian dalam belajar, karena semua kegiatan atau materi diperoleh dari pengajar. Mahasiswa belum dapat mengembangkan materi tentang budaya Jepang yang diterima. Sedangkan salah satu tujuan proses pembelajaran, pembelajar memiliki daya pikir kritis untuk dapat memotivasi seseorang dalam memunculkan ide-ide baru.

Berdasarkan permasalahan di atas, maka peneliti mempraktekkan kegiatan yang berbeda dari sebelumnya yaitu aktivitas proyek biasa disebut dengan project based learning. Boss dan Kraus, mengatakan pembelajaran Berbasis Proyek adalah sebuah pembelajaran yang menekankan aktivitas siswa dalam memecahkan berbagai permasalahan yang bersifat open-ended dan mengaplikasi pengetahuan mereka dalam mengerjakan sebuah proyek untuk menghasilkan sebuah produk otentik tertentu (Abidin, 2007:167).

Pembelajaran menggunakan metode ini akan menghasilkan produk berupa poster yang akan di presentasikan oleh pembelajaran yang mengikuti perkuliahan nihonjijo. Pembelajar dapat memahami budaya dengan 3 tahap yaitu: (1)Practise, (2) Products, (3) Perspective . Dapat dilihat pada gambar 1.(Matsumoto, 2016:15) dibawah ini: 


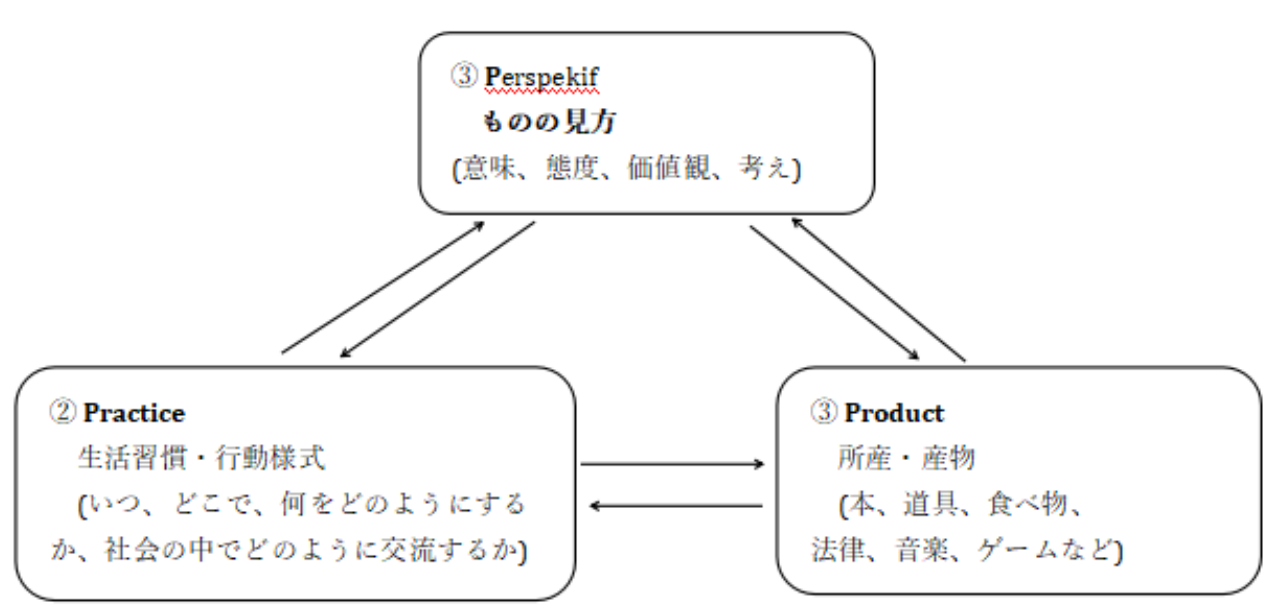

Gambar 1. Pemahaman budaya 3P

\section{METODE PENELITIAN}

Metode penelitian yang digunakan yaitu metode deskriptif kualitatif. Populasi penelitian adalah mahasiswa program studi pendidikan bahasa Jepang Universitas Negeri Semarang. Sampel penelitian, mahasiswa semester 1 tahun ajaran 2019/2020 yang mengikuti perkuliahan nihonjijo sebanyak 32 mahasiswa.Teknik pengumpulan data yang digunakan adalah observasi dan angket. Observasi dilakukan untuk memperoleh data, apakah terdapat daya pikir kritis mahasiswa ketika mengikuti kegiatan pembelajaran berbasis proyek. Sedangkan angket bertujuan untuk memperoleh kesan mahasiswa terhadap pembelajaran berbasis proyek.

\section{HASIL DAN PEMBAHASAN}

Pembelajaran berbasis proyek ini dilakukan pada $3 x$ pertemuan., terdiri dari:

Pertemuan pertama (2 sks/100 menit): penjelasan pembelajaran berbasis proyek, pembagian kelompok menjadi 8 kelompok (masing-masing kelompok terdiri 4 mahasiswa), penentuan tema (1. Upacara minum teh, 2. Kereta api di Jepang, 3. Perayaan Kawagoe, 4. Seragam sekolah di Jepang, 4. Bekal di Jepang, 5. Penanggulangan gempa di Jepang, 6. Ninja, 7. Seragam 
sekolah, dan 8). Tema tidak ditentukan oleh pengajar. Mahasiswa diberi kebebasan memilih tema sesuai dengan ruang lingkup budaya Jepang.

Mahasiswa dapat mencari informasi, dari pengajar lain atau kakak tingkat atau kenalan orang Jepang dalam bentuk wawancara dan dapat melalui buku atau internet.

Pertemuan kedua (2 sks/100menit): penyusunan materi berdasarkan $3 \mathrm{P}$ (Praktik, Produk Perspektif). Pengajar mengecek informasi yang telah diperoleh masing-masing kelompok, lalu mengoreksi jika ditemui kekeliruan. Dan penyusunan gambar dan tulisan pada kertas yang akan menjadi sebuah poster.

Pertemuan ketiga 2 sks/100 menit: pembuatan poster, poster dapat dibuat di rumah atau jika belum selesai diberikan waktu 15-30 menit di kelas. Lalu persiapan presentasi. Presentasi dilakukan 2 tahap. Tahap pertama, 4 kelompok pertama presentasi bersamaan namun tempat berbeda, 4 kelompok yang lain silakan memilih akan menyimak kelompok yang mana. Presentasi dan tanya jawab dilakukan 4 kali. Jadi ada 4 kali kesempatan presentasi dan 4 kelompok lain memiliki 4 kali kesempatan mendengarkan presentasi pada kelompok yang berdeda. Tahap kedua, 4 kelompok selanjutnya, dilakukan seperti pada tahap pertama. Proses pembelajaran pembuatan poster dapat di lihat pada gambar 1. dan gambar 2 .

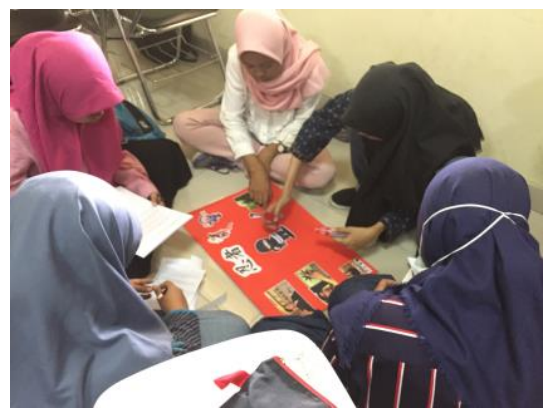

Gambar 1. Menempel gambar tema "Ninja”

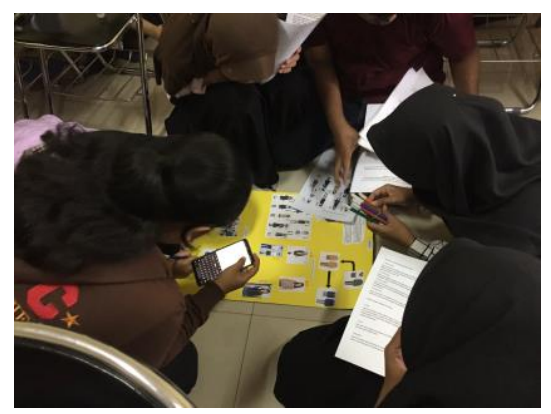

Gambar 2. menempel gambar tema seragam

Setelah mahasiswa melaporkan isi poster dan tanya jawab, mahasiswa yang menyimak menuliskan komentar pada lembar komentar tentang 
penampilan saat presentasi dan isi poster. Komentar ini bertujuan sebagai motivasi atau evaluasi.

Hasil observasi:

1) Delapan kelompok dengan delapan tema, terdapat berbagai macam gambar dan tulisan serta isi pembahasan. Hal menunjukkan bahwa mahasiswa memiliki ide-ide dan gagasan serta pemikiran kritis dalam menentukan tema.

2) Dalam penentuan tema, terdapat tema "ninja". Tidak ada dalam lingkup budaya Jepang. Ini menunjukkan bahwa mahasiswa dapat berpikir kreatif. Kreatif dalam memperoleh informasi dan menyusunan ide untuk dipresentasikan.

3) Mahasiswa dapat menyelesaikan masalah dalam pembelajaran berbasis proyek ini, mereka dapat menyusun secara tugas secara mandiri dalam kelompok, menetukan apa saja poin termasuk pada 3 P (Praktik, Produk dan Perspektif). Meskipun pengajar tetap mengontrol dan mengoreksi, namun mereka dapat menemukan sendiri ide untuk dipresentasikan. Contoh dari pembahasan: tema "bekal". Praktik: dibawa ke sekolah, kantor, berwisata atau piknik. Produk: bekal buatan rumah, bekal praktis, bekal yang dijual di supermarket dan Perspektif: tujuan bekal, perkembangan bekal, bentukbentuk bekal. Ini menunjukkan mahasiswa secara mandiri dapat memperoleh informasi tentang bekal dan mereka dapat berpikir kreatif yaitu dengan menemukan dan menyusun poster dan pembahasan akan dipresentasikan.

Hasil angket: untuk mengetahui kesan mahasiswa setelah mengikuti pembelajaran nihonjijo melalui pembelajaran berbasis proyek. Pilihan pada pernyataan angket jenis pertama adalah sangat setuju, setuju, tidak setuju dan sangat tidak setuju, sedangkan pilihan pernyataan angket jenis kedua adalah pilihan objektif. Dari hasil analisis dapat diperoleh data:

1. Pembelajaran nihonjijo berbasis proyek, saya dapat mengungkapkan ide dalam kelompok. Dari 32 responden: 25\% responden menjawab sangat 
setuju, 69\% responden menjawab setuju, 6\% responden menjawab tidak setuju dan $0 \%$ responden yang menjawab sangat tidak setuju. Maka sebagian besar yaitu 94\% mahasiswa yang mengikuti perkuliahan nihonjijo berbasis proyek dapat mengungkapkan ide atau gagasan dalam kelompok.

2. Melalui pembelajaran berbasis proyek saya memahami budaya Jepang secara spesifik. Dari 32 responden: 28\% responden menjawab sangat setuju, $65 \%$ responden menjawab setuju, sedangkan 5\% responden menjawab tidak setuju dan 2\% responden menjawab sangat tidak setuju. Dari hasil angket tersebut, dapat dikatakan bahwa 93\% mahasiswa memahami budaya Jepang secara spesifik melalui pembelajaran berbasis proyek.

3. Saya mendapatkan informasi pembahasan sesuai tema yang dipilih dari:

a. Internet atau buku.

b. Dosen bahasa Jepang.

c. Kenalan orang Jepang

Dari 3 pilihan jawaban di atas, responden yang memilih jawaban poin a. sebesar $81 \%$, mendapatkan informasi pembahasan melalui buku atau internet, $13 \%$ responden memilih poin b. yaitu mendapatkan informasi dari dosen bahasa Jepang dan 6\% responden memilih poin c. mendapatkan informasi dari kenalan orang Jepang. Jadi, sebagian besar secara mandiri medapatkan informasi dari buku atau internet.

\section{KESIMPULAN}

Berdasarkan hasil dan pembahasan dapat disimpulkan bahwa pembelajaran budaya (nihonjijou) melalui pembelajaran berbasis proyek, yang menghasil produk berupa poster. Hasil observasi menunjukkan, bahwa mahasiswa dapat berpikir kritis: ditujukan oleh pemilihan tema diluar lingkup budaya yakni "Ninja”, kreatif: tidak ada gambar atau tema yang sama yang mahasiswa pilih dan mandiri: mendapatkan informasi awal dari berbagai sumber dalam menyelesaikan poyek pembelajaran. Hasil angket 
menunjukkan pembelajaran nihonjijo melaui pembelajaran berbasis proyek 94\% mahasiswa yang mengikuti perkuliahan nihonjijo berbasis proyek dapat menjadikan mahasiswa dapat mengungkapkan daya pikir kritis melalui penyampaian ide dan gagasan dalam kelompok dan 100\% dapat belajar mandiri yaitu memperoleh informasi budaya Jepang dari buku, internet, dosen bahasa Jepang dan kenalan orang Jepang.

\section{REFERENSI}

Abidin, Zainal. 2007. Analisis eksistensial. Jakarta: Raja Grafindo.

Chaer, Abdul. 2003. Psikolinguistik, kajian teoretik. Jakarta: Rineka Cipta

Hashimoto, Keiji. 2015. Nihongo Kyouiku ni okeru (Nihongo Jijo) -Shokyu Nihongo Kyouzai ni Mirareru (Nihonjijo)- https://ir.lib.hiroshimau.ac.jpdiakses 11 Januari 2020

Matsumoto, Kou. 2016. Nihonjijo Nihonbunka o Oshieru. Japan Foundation: Tokyo 